\title{
Consanguineous Marriages and Their Effects on Common Adult Diseases: Studies from an Endogamous Population
}

\author{
Abdulbari Bener $^{a, b}$ Rafat Hussain ${ }^{c} \quad$ Ahmad S. Teebi $^{d}$ \\ a Department of Medical Statistics and Epidemiology, Hamad General Hospital, Hamad Medical Corporation, \\ Doha, Qatar; ${ }^{b}$ Evidence for Population Health Unit, School of Epidemiology and Health Sciences,

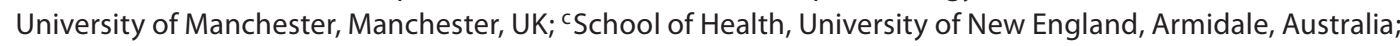 \\ ${ }^{\mathrm{d}}$ Division of Clinical and Metabolic Genetics, Hospital for Sick Children, Toronto, Ont., Canada
}

\section{Key Words}

Consanguinity, diseases · Epidemiology $\cdot$ Genetics •

Population-based study

\begin{abstract}
Objectives: The aim of the study was to determine the extent and nature of consanguinity in the Qatari population and its effects on common adult diseases. Subjects and Methods: The study was conducted in urban and semi-urban areas of Qatar between October 2004 and May 2005. The total sample of 1,050 married Qatari females 15 years of age and over were approached for study. The degree of consanguinity between each female and her spouse and the degree of consanguinity between their parents were recorded. Results: Of 1,050 married Qatari females who were approached, 876 agreed to participate in the study, giving an $83.4 \%$ response. The rate of consanguinity in the present generation was $51 \%$ (95\% confidence interval $=47.7-54.4$ ) with a coefficient of inbreeding of 0.023724 . The consanguinity rate and coefficient of inbreeding in the current generation were significantly higher than the maternal rate (51.0 vs. $40.3 \% ; p<0.001 ; 0.023724$ vs. 0.016410 maternal). All types of consanguineous marriages were higher in this generation, particularly first cousins ( 26.7 vs. $21.4 \%$ paternal and $23.1 \%$ maternal) and double first cousins ( 4.3 vs. $2.9 \%$ pater-
\end{abstract}

(C) 2007 S. Karger AG, Basel

1011-7571/07/0164-0262\$23.50/0

Fax +41613061234

E-Mail karger@karger.ch

www.karger.com
Accessible online at:

www.karger.com/mpp nal and $0.8 \%$ maternal). The current generation of consanguineous parents had a slightly higher risk for most diseases: cancer, mental disorders, heart diseases, gastro-intestinal disorders, hypertension, hearing deficit and diabetes mellitus. All reported diseases were more frequent in consanguineous marriages. Conclusion: The study showed that in a population with a high rate of consanguinity, there is a significant increase in the prevalence of common adult diseases like cancer, mental disorders, heart diseases, gastro-intestinal disorders, hypertension and hearing deficit.

Copyright $\odot 2007$ S. Karger AG, Basel

\section{Introduction}

There is a historically high prevalence of consanguineous marriages in many communities throughout the world, especially in countries of the Middle East, Northern Africa and South Asia [1-5]. While the rate of consanguinity varies within the Middle East, the difference is usually related to religion, race, ethnicity and sociocultural factors, including socially accepted norms of endogamy in tribal societies [6]. Among the major populations studied, the highest rates of consanguineous marriages have been associated with socio-economic levels, illiteracy and rural residence [7-16]. Recent studies show that 
$68 \%$ of all marriages in Alexandria, Egypt, are consanguineous [7], while the prevalence in Jordan $[8,9]$ varies from 51 to $58 \%$; it is $54 \%$ in Kuwait [1], 58\% in Saudi Arabia [10], 50\% in the United Arab Emirates [6], 52\% in Qatar [11, 12], 40-47\% in Yemen [13, 14], 50\% in Oman [15] and $38.6 \%$ in Iran [16].

Numerous reports on the effect of inbreeding on health have focused mainly on its impact on reproduction, childhood mortality and rare mendelian disorders [5, 17-20]. Nevertheless, very limited information is available on the possible role of consanguinity and recessive genes in multifactorial or polygenic common adult diseases $[4,12,21]$. In the present study, the impact of high consanguinity on the prevalence of common adult diseases in the Qatari population was investigated.

\section{Subjects and Methods}

A cross-sectional study was conducted in the State of Qatar between October 2004 and May 2005 to determine the impact of consanguineous marriages on common diseases. A multistage stratified cluster sampling design was developed using an administrative division of Qatar in terms of number of inhabitants into 21 primary health centres. Over 70\% of Qatari women visited just 10 health centres, which proportionately represented the Qatari population.

An estimate of $50 \%$ for prevalence of consanguinity as reported in neighbouring countries $[4,6,10,11,13-15]$ and level of significance (type I error) of $1 \%$, for computing $99 \%$ confidence limits with $4 \%$ error bound, was used to give an estimate of a sample size of 1,050 women. A multistage stratified sampling design was performed with subjects being selected by simple random sampling. Hence, a sample of 1,050 married Qatari females aged 15 years and above were selected for this study; 876 agreed to participate while the remaining subjects were excluded because some refused to take part and others submitted incomplete questionnaires. All information was gathered based on structured face-to-face interviews by physicians and qualified nurses using the local language. Furthermore, content validity, face validity and reliability of the questionnaire were tested in a sample of 150 subjects and demonstrated high levels of validity and a high degree of repeatability $(\kappa=0.81) ; 78 \%$ of self-reported diseases were confirmed in medical charts. The relationship between the spouses was recorded as was whether their parents were consanguineous. Marriages between relatives were classified in 6 groups: double first cousins; first cousins; first cousin once removed; second cousin; less than second cousin (third cousin), and non-consanguineous marriage.

The category of first cousin was then further divided into 4 types: paternal and maternal parallel types I and II and crosscousin types III and IV as shown in figure 1. The average level of inbreeding was assessed in terms of coefficient of kinship values for each population $\left(\alpha=\Sigma p_{i} F_{i}\right)$ where $\alpha$ measures the probability that a gene taken at random from one spouse is identical by descent to a gene from the same locus taken at random from his/her partner [22].

Consanguinity and Its Effect on Diseases

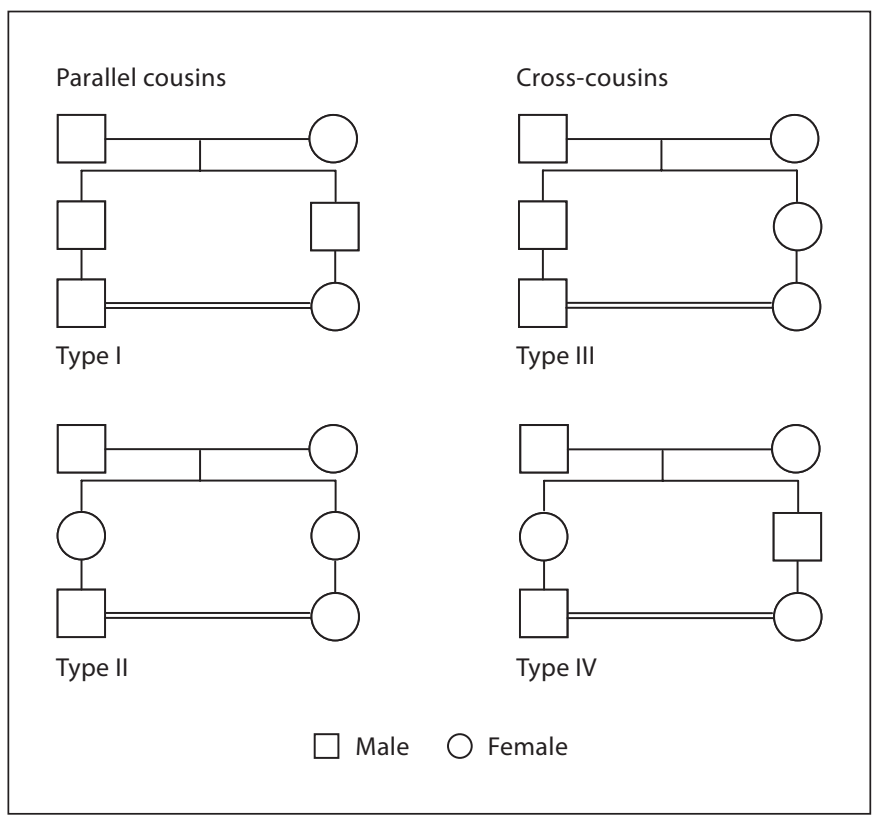

Fig. 1. Types of first-cousin marriages.

Odds ratios were computed for the likelihood of disease by consanguinity status in the current generation as well as the respondent's children. For the current generation, cases were defined as respondents who were offspring of consanguineous unions (disease report limited to either self or siblings having the disease), and controls were defined as respondents who were offspring of non-consanguineous unions (disease report limited to either themselves or siblings having the disease). Similarly definitions were adopted for respondent's offspring. The $\chi^{2}$ test was used to ascertain the association between two or more categorical variables. In $2 \times 2$ tables, the Fisher exact test (two-tailed) was used when the sample size was small. Relative risk and $95 \%$ confidence interval were calculated using the Mantel-Haenszel method. The level $\mathrm{p}<0.05$ was the cut-off value for significance.

\section{Results}

The mean age \pm SD of the 876 women interviewed was $39.25 \pm 9.57$ years. The rate of consanguinity in the present generation was $51 \%$ ( $95 \%$ confidence interval = 47.7-54.4). The sociodemographic characteristics of consanguineous and non-consanguineous distribution in the study population are shown in table 1. A significant association was observed between respondents' educational level and consanguinity. More consanguineously married women $(252,56.4 \%)$ were reported being illiterate than non-consanguineously married women (204, $47.6 \%$ ). Conversely women with university education 
were less likely to be married to cousins $(52,12.1 \%$ of nonconsanguineously married women compared to those in consanguineous unions, i.e. $30,6.7 \%)$. Although a similar pattern between consanguinity and husband's education was observed, the differences were smaller and not statistically significant. While the majority of women in both groups were housewives, no clear pattern was evident in consanguinity pattern relation to husband's occupation. Socio-economic status showed that the majority of the respondents $(278,62.2 \%$, consanguineous and $252,58.7 \%$, non-consanguineous marriages) belonged to the low socio-economic group. A U-shaped association was observed between socio-economic status and consanguinity, with higher levels of consanguineous unions reported amongst those with low and high socio-economic status compared to those who reported to have medium-level socio-economic status.

Data on trends in levels of consanguinity in the current generation compared to the parental generation and the associated coefficient of inbreeding are presented in table 2. The most common type of consanguineous marriage was first-cousin marriage $(233,26.7 \%)$. Of these, type I (patrilateral parallel cousin marriages) constituted 154 of the total 233 marriages of first-cousin unions, while type II (patrilateral cross-cousin marriages) constituted $2.5 \%$ of all marriages, type III $2.9 \%$ and type IV $3.7 \%$. The second most common category of consanguineous marriages was double first-cousin marriages (38, $4.3 \%)$. The prevalences of marriages between first cousins once removed and second cousins were 3.9 and 3.0\%, respectively, while $13.2 \%$ of all marriages were between more distant cousins (table 2). The rate of consanguinity in the parental generation was similar in the respondent's parents $(51.0 \%)$, whereas the consanguinity rate among the respondent's husband's parents was $32.0 \%(\mathrm{p}<0.001)$. The coefficient of inbreeding in the respondent, husband's parents and respondent's parents were 0.023724, 0.018425 and 0.016410 , respectively. All types of consanguineous marriages were higher in the respondent's generation, particularly first cousin ( 26.7 vs. $21.4 \%$ paternal and $23.1 \%$ maternal) and double first cousins (4.3 vs. $2.9 \%$ paternal and $0.8 \%$ maternal).

The prevalence of common adult diseases among parents and the current generation and their offspring by consanguineous versus non-consanguineous mating in the Qatari population is presented in table 3. Data show that there was a statistically significant difference in the two groups, parents and the current generation, in relation to cancer, blood disorders and bronchial asthma. Moreover, the current generation of consanguineous par-
Table 1. Sociodemographic information and consanguinity among subjects

\begin{tabular}{|c|c|c|c|}
\hline Variables & $\begin{array}{l}C \\
(n=447)\end{array}$ & $\begin{array}{l}\text { NC } \\
(n=429)\end{array}$ & $\begin{array}{l}\mathrm{p} \\
\text { value }\end{array}$ \\
\hline \multicolumn{4}{|l|}{ Age group } \\
\hline$<25$ years & $16(3.6)$ & $16(3.7)$ & \multirow{4}{*}{ NS } \\
\hline $25-34$ years & $68(15.2)$ & $76(17.7)$ & \\
\hline $35-44$ years & $195(43.6)$ & $173(40.3)$ & \\
\hline$\geq 45$ years & $168(37.6)$ & $164(38.2)$ & \\
\hline \multicolumn{4}{|l|}{ Wife's education } \\
\hline Illiterate & $252(56.4)$ & $204(47.6)$ & \multirow{4}{*}{0.001} \\
\hline Primary & $113(25.3)$ & $97(22.6)$ & \\
\hline Secondary and high school & $52(11.6)$ & $76(17.7)$ & \\
\hline University and above & $30(6.7)$ & $52(12.1)$ & \\
\hline \multicolumn{4}{|l|}{ Husband's occupation } \\
\hline Business & $21(4.7)$ & $27(6.3)$ & \multirow{3}{*}{ NS } \\
\hline Sedentary & $274(61.3)$ & $250(58.3)$ & \\
\hline Manual & $152(34.0)$ & $152(35.4)$ & \\
\hline \multicolumn{4}{|l|}{ Wife's occupation } \\
\hline Business & $13(2.9)$ & $24(5.6)$ & \multirow{4}{*}{ NS } \\
\hline Housewife & $340(76.1)$ & $321(74.8)$ & \\
\hline Sedentary & $80(17.9)$ & $69(16.1)$ & \\
\hline Manual & $14(3.1)$ & $15(3.5)$ & \\
\hline \multicolumn{4}{|l|}{ Husband's education } \\
\hline Illiterate & $197(44.1)$ & $173(40.3)$ & \multirow{4}{*}{ NS } \\
\hline Primary & $103(23.0)$ & $115(26.8)$ & \\
\hline Secondary and high school & $100(22.4)$ & $87(20.3)$ & \\
\hline University and above & $47(10.5)$ & $54(12.6)$ & \\
\hline \multicolumn{4}{|l|}{ Socio-economic status } \\
\hline Low & $278(62.2)$ & $252(58.7)$ & \multirow{3}{*}{0.015} \\
\hline Medium & $69(15.4)$ & $48(11.2)$ & \\
\hline High & $100(22.4)$ & $129(30.1)$ & \\
\hline \multicolumn{4}{|l|}{ Parental consanguinity } \\
\hline \multicolumn{4}{|c|}{ Wife's parents consanguineous } \\
\hline Yes & $187(41.8)$ & $166(38.7)$ & \multirow{2}{*}{ NS } \\
\hline No & $260(58.2)$ & $263(61.3)$ & \\
\hline \multicolumn{4}{|c|}{ Husband's parents consanguineous } \\
\hline Yes & $227(50.8)$ & $141(32.9)$ & \multirow{2}{*}{$<0.001$} \\
\hline No & $220(49.2)$ & $288(67.1)$ & \\
\hline
\end{tabular}

$\mathrm{C}=$ Consanguineous; $\mathrm{NC}=$ non-consanguineous; $\mathrm{NS}=$ not significant. Figures in parentheses indicate percentages.

ents had a significantly higher risk than the non-consanguineous parents for such diseases as cancer, mental disorders, heart diseases, gastro-intestinal disorders, hypertension, hearing deficit and diabetes mellitus. There was also a significant difference in the prevalence between the offspring of consanguineous versus non-consanguineous mating for cancer cases. All reported diseases were more frequent in consanguineous marriages. 
Table 2. Consanguinity in the current generation compared to the parental generation

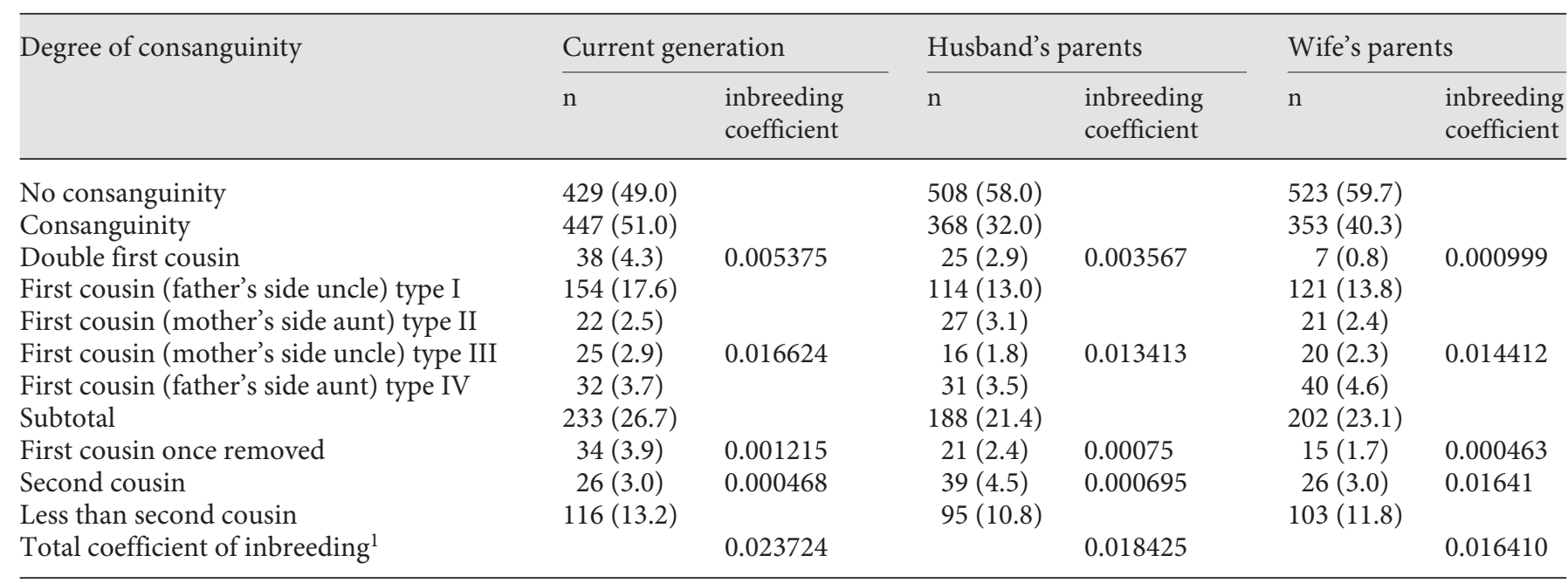

Figures in parentheses indicate percentages.

${ }^{1}$ Inbreeding coefficient up to 2 nd cousins.

Table 3. Prevalence of common adult diseases among the current generation and offspring by consanguineous and non-consanguineous unions

\begin{tabular}{|c|c|c|c|c|}
\hline & $\mathrm{C}$ & $\mathrm{NC}$ & OR & $\mathrm{p}$ value \\
\hline Current generation & $\mathrm{n}=330$ & $\mathrm{n}=523$ & & \\
\hline Cancer & 36 & 8 & $7.88(3.46-18.64)$ & $<0.001$ \\
\hline Blood disorders & 27 & 13 & $3.50(1.70-7.27)$ & $<0.001$ \\
\hline Mental disorders & 9 & 3 & $4.86(1.20-22.78)$ & 0.009 \\
\hline Heart diseases & 27 & 17 & $2.65(1.37-5.18)$ & 0.002 \\
\hline Bronchial asthma & 22 & 8 & $4.60(1.92-11.38)$ & $<0.001$ \\
\hline GI disorders & 10 & 6 & $2.69(0.88-9.09)$ & 0.048 \\
\hline Hypertension & 27 & 5 & $9.23(3.34-27.60)$ & $<0.001$ \\
\hline Hearing deficit & 7 & 1 & $11.31(1.40-245.78)$ & 0.004 \\
\hline DM & 46 & 24 & $3.37(1.96-5.82)$ & $<0.001$ \\
\hline Offspring & $\mathrm{n}=447$ & $\mathrm{n}=429$ & & \\
\hline Cancer & 45 & 13 & $3.58(1.84-7.10)$ & $<0.001$ \\
\hline Blood disorders & 17 & 8 & $2.08(0.84-5.31)$ & 0.085 \\
\hline Mental disorders & 1 & 3 & $0.32(0.01-3.42)$ & 0.364 \\
\hline Heart diseases & 38 & 31 & $1.19(0.71-2.01)$ & 0.484 \\
\hline Bronchial asthma & 17 & 22 & $0.73(0.37-1.46)$ & 0.342 \\
\hline GI disorders & 15 & 7 & $2.09(0.79-5.72)$ & 0.103 \\
\hline Hypertension & 22 & 14 & $1.53(0.74-3.21)$ & 0.217 \\
\hline Hearing deficit & 7 & 1 & $6.81(0.84-147.88)$ & 0.070 \\
\hline DM & 47 & 36 & $1.28(0.79-2.07)$ & 0.283 \\
\hline
\end{tabular}

$\mathrm{C}=$ Consanguineous; $\mathrm{NC}=$ non-consanguineous; $\mathrm{OR}=$ odds ratio; $\mathrm{GI}=$ gastro-intestinal; $\mathrm{DM}=$ diabetes mellitus. Figures in parentheses indicate $95 \%$ confidence intervals. 


\section{Discussion}

The incidence of consanguinity is relatively high in Qatar, with a rate of $51.0 \%$, and predominantly first-cousin marriages comprising $26.7 \%$ of all marriages. The most common pattern of first-cousin unions was type 1 (paternal parallel first cousin), which constituted $17.6 \%$ of all marriages, similar to other Arab countries, where there is a tradition of consulting with male siblings, before agreeing to the marriage of a daughter to a non-relative $[1,8,10,14,15,23,24]$. While we do not have empirical data, we believe the preference is related to the deeply rooted cultural beliefs, social life and customs. Such marriages are considered to be more stable, due to close similarities in social and cultural values between the couple, and the economic benefits of keeping wealth within the families [6-12].

The excess risk that an autosomal recessive disorder could be expressed in the progeny of a consanguineous union is inversely proportional to the frequency of the disease allele in the total gene pool [5]. For this reason, during the last decade many rare disease genes have been identified and their chromosomal locations mapped by studying highly inbred families with multiple affected members $[25,26]$. The main impact of inbreeding is an increase in the rate of homozygotes for recessive disorders $[6,19,27]$. It is believed, although not proven, that high rates of inbreeding over multiple generations lead to elimination of deleterious recessive genes from the gene pool [27]. However, studies from South India where inbreeding has been practised for more than 2,000 years showed that there has been no appreciable elimination of recessive lethal and sublethal genes in the gene pool [28]. In an Eastern province of Saudi Arabia [29], the rate of consanguineous marriage was $52.0 \%$ with an average inbreeding coefficient of 0.0312 , slightly higher than that of the present study where the coefficients of inbreeding in the respondent, husband's parents and wife's parents are $0.023724,0.018425$ and 0.016410 , respectively.

It has been reported that several genetic disorders, congenital malformations and reproductive wastage are more frequent in consanguineous marriages [30]. The risk for birth defects in the offspring of first-cousin marriage has been estimated to increase sharply compared to non-consanguineous marriages [31]. In several countries, the occurrence of malignancies, congenital abnormalities, mental retardation and physical handicap was significantly higher in offspring of consanguineous than non-consanguineous marriages [6-32], similar to the findings in the present study (table 3 ).
Those findings showed that consanguinity did not result in reproductive wastage but was an important factor in causing specific illnesses in offspring. Close consanguinity has probably been practised in the Gulf countries $[1-3,6,11-15]$, including Qatar for over 100 generations.

Some of the limitations of this study include the fact that over half of our study sample belonged to the low socio-economic status. The quality of health services in Doha and semi-urban areas of Qatar is high, and access to good-quality medical care is not an issue for most of the population. The absence of a comprehensive disease registry and database makes it difficult to make a sound assessment of the health impact of consanguinity at the community level. Furthermore, it is worth noting that there might be some bias in data associated with the ages of participants and reporting of diseases such as cancer, hypertension, diabetes and coronary heart diseases, which may arise later in life (in both cases and controls). Further in-depth studies are needed to determine the consanguinity rates in relation to morbidity and mortality in this population because consanguinity is increasing in the current generation, in spite of better education.

\section{Conclusion}

This study shows a higher incidence of certain diseases in consanguineous couples and that, in a population with a high rate of consanguinity, there is a significant increase in the prevalence of common adult diseases: cancer, mental disorders, heart diseases, gastro-intestinal disorders, hypertension, hearing deficit and diabetes mellitus.

\footnotetext{
References $\nabla_{1}$ Al-Awaadi SA, Moussa MA, Naguib KK, Farag TI, Teebi AS, El-Khalifa M, El-Dossary L: Consanguinity among the Kuwait population. Clin Genet 1985;27:483-486.

2 Al-Ghazali, LI, Al-Wash R, Abdulrazzaq MY: United Arab Emirates: communities and community genetics. Community Genet 2005;8:186-196.

-3 Bener A, Zirie M, Al-Rikabi R: Genetics, obesity and environmental risk factors associated with type 2 diabetes. Croat Med J 2005;46:302-307.

4 Jaber L, Shohat T, Rotter JI, Shohat M: Consanguinity and common adult diseases in Israeli Arab communities. Am J Med Genet 1997;70:346-348.
} 
5 Bittles AH, Grant J, Sullivan SG, Hussain R: Does inbreeding lead to decreased human fertility? Ann Hum Biol 2002;29:111-130.

-6 Bener A, Abdulrazzaq MY, Al-Gazali LI, Micallef R, Al-Khayat AI, Gaber T: Consanguinity and associated socio-demographic factors in the United Arab Emirates. Hum Hered 1996;46:256-264.

7 Mokhtar MM, Abdel-Fattah M: Major birth defects among infants with Down syndrome in Alexandria, Egypt (1995-2000): trends and risk factors. East Mediterr Health J 2001; 7:441-451.

8 Khoury SA, Massad D: Consanguineous marriage in Jordan. Am J Med Genet 1992; 43:769-775.

9 Sueyoshi S, Ohtsuka R: Effects of polygyny and consanguinity on high fertility in the rural Arab population in South Jordan. J Biosoc Sci 2003;35:513-526.

10 El-Hazmi MAF, Al-Swailem AR, Warsy AS, Al-Swailem AM, Sulaimani R, Al-Meshari AA: Consanguinity among Saudi Arabian population. J Med Genet 1995;32:623-626.

11 Bener A, Al-Ali K: Consanguineous marriage in a newly developed country: the Qatari population. J Biosoc Sci 2006;38:239246.

12 Bener A, Hussain R: Consanguineous unions and child health in the State of Qatar. Paediatr Perinat Epidemiol 2006;20:372-378.

13 Jurdi R, Saxena PC: The prevalence and correlates of consanguineous marriages in Yemen: similarities and contrasts with other Arab countries. J Biosoc Sci 2003;35:1-13.

14 Gunaid AA, Hummad NA, Tamim KA: Consanguineous marriage in the capital city Sana'a, Yemen. J Biosoc Sci 2004;36:111121.
15 Rajab A, Patton MA: A study of consanguinity in the Sultanate of Oman. Ann Hum Biol 2000;27:321-326

16 Saadat M, Ansari-Lari M, Farhud DD: Consanguineous marriage in Iran. Ann Hum Biol 2004;31:263-269.

17 Charlesworth B, Hughes KA: The maintenance of genetic variation in life history traits; in Singh RS, Krimbas CB (eds): Evolutionary Genetics: From Molecules to Morphology. Cambridge, Cambridge University Press, 1999, vol 1.

18 Ben Arab S, Masmoudi S, Beltaief N, Hachicha S, Ayadi H: Consanguinity and endogamy in Northern Tunisia and its impact on non-syndromic deafness. Genet Epidemio 2004;27:74-79.

19 Bittles AH: Consanguineous marriage and childhood health. Dev Med Child Neurol 2003;45:571-576

20 Wright AF, Hastie ND: Complex genetic diseases: Controversy over the Croesus code. Genome Biol 2001;2:1-8.

21 Bener A, Denic S, Al-Mazrouei M: Consanguinity and family history of cancer in children with leukaemia and lymphomas. Cancer 2001;92:1-6.

22 Emery A: Methodology in medical genetics. An Introduction to Statistical Methods. Edinburgh, Churchill Livingstone, 1976, p 20.

23 Khlat M, Khoury M: Inbreeding and diseases: demographic, genetics and epidemiologic perspectives. Epidemiol Rev 1991;13:28-41.

-24 Tamim H, Khogali M, Beydoun H, Melki I, Yunis K: National Collaborative Perinatal Neonatal Network: consanguinity and apnea of prematurity. Am J Epidemiol 2003 158:942-946.
25 Moynihan L, Houseman M, Newton V, Mueller R, Lench N: DFNB20: a novel locus for autosomal recessive, non-syndromal sensorineural hearing loss maps to chromosome 11q25-qter. Eur J Hum Genet 1999;7: 243-246.

26 McHale DP, Jackson AP, Campbell DA, Levene MI, Corry P, Woods CG, Lench NJ, Mueller RF, Markham AF: A gene for ataxic cerebral palsy maps to chromosome 9p12q12. Eur J Hum Genet 1999;8:267-272.

27 Roberts JAF, Pembrey ME: Cousin marriage in Roberts JAF, Pembrey ME (eds): An Introduction to Medical Genetics. New York, Oxford University Press, 1978, p 295.

28 Devi ARR, Rao NA, Bittles AH: Inbreeding and the incidence of childhood genetic disorders in Karnataka, South India. J Med Genet 1987;24:362-365.

29 Al-Abdulkareem AA, Ballal SG: Consanguineous marriage in an urban area of Saudi Arabia: rates and adverse health effects on the offspring. J Community Health 1998;23: 75-83.

30 Bittles AH, Mason WM, Greene J, Rao NA: Reproductive behaviour and health in consanguineous marriages. Science 1991;252: 789-794

31 Stoll C, Alembik Y, Roth MP, Dott B: Parental consanguinity as a cause for increased incidence of birth defects in a study of 238,942 consecutive births. Ann Genet 1999;42:133139.

32 Abdulrazzaq YM, Bener A, Al-Gazali LI, AlKhayat AI, Micallef R, Gaber T: A study of possible deleterious effects of consanguinity. Clin Genet 1997;51:167-173. 